\title{
DO BOYS AND GIRLS GO OUT TO PLAY? WOMEN'S FOOTBALL AND SOCIAL MARKETING
}

Paul Blakey, Northumbria University, United Kingdom, paul.blakey@unn.ac.uk

Barbara Bell, Edge Hill University, Uinted Kingdom

\section{INTRODUCTION}

Football dominates popular sport in the UK, both in terms of spectators and the viewing public (MORI, 2004). However, football is not equally popular for male and female audiences and research has shown that despite a growing female audience for the game, it remains male dominated (Williams, 2003). Participation rates and media coverage follow a similar pattern, clearly, therefore, football is not a game of two halves, when we consider gender.

This paper addresses the development of women's football in the UK. It focuses upon EURO 2005 - a tournament used to generate considerable appeal for women's football within the public of the UK. The paper highlights some key historical occurrences, considers the influence of the male game, and utilises the philosophy of social marketing to assess the social proposition offered by the tournament in order to develop further the concept of 'social sport marketing'.

It is important to recognise that the form of sport individuals may choose to play is a complex of personal taste, socialisation, even fashion. Women's football presents an interesting case study to consider how attitudes to sport can be influenced, to help increase the likelihood that young women in particular will play. EURO 2005 identified its desire to influence voluntary behaviour, over a long period, along with affecting social change, in terms of public attitudes and support.

Social marketing focuses the offering of a social proposition (Peattie \& Peattie, 2003) on influencing social behaviours to effect behaviour change proposing a 'relational' rather than 'transactional' philosophy (Hastings, as cited by Beishon, 2005). It has gained acceptance as an aid to positive social change in the areas of health, injury prevention, environmental protection and community involvement (Peattie \& Peattie, 2003). As community sport addresses social issues such as health, crime, diversity and social inclusion, the two philosophies form a natural affinity in the development of social sport marketing.

The connection between sport and social marketing has been identified in Game Plan (Stratgey Unit/ DCMS, UK, 2002), with the concept of 'social sport marketing' presented through a model of 'Social Sport Marketing'. The model borrows heavily from the 'Stages of Changes' model (Prochaska \& DiClemente, 1983) suggesting that behaviour change is brought about through a series of marketing actions that move an individual from indifference (Stage1: Pre-contemplation - creating awareness and changing values) towards a sporting activity, through realisation of (Stage2: Contemplation - persuading and motivating and Stage 3: Preparation - creating action), and commitment to (Stage 4: Action - enabling action and Stage 5: Confirmation/Maintenance - maintaining change), participation. Collins (2004) noted that any application of a principle of social sport marketing is currently rudimentary and needs to be better informed. This area has some on-going research interest, but little has been forthcoming to date in established academic outlets.

\section{METHODS}

In order to analyse the application of 'Social Sport Marketing' at EURO 2005, semi-structured interviews were conducted with the Women's Football Development Officer at the FA, members of the Legacy 
Programme Steering Group and the consultants responsible for the Legacy programme. Additionally, participant observation at a number of the games enabled assessment of the effects of social sport marketing activities. Secondary data analysis of spectator figures was also undertaken. Data interpretation and analysis reflected the conceptual framework of the model of social sport marketing against which deduction occurred.

\section{RESULTS}

The concept of 'social sport marketing', and its emergent model, was seen to have some application to women's football through Euro 2005. At stage 1 (Pre-contemplation), activities were focused on the event road shows and festivals promoting the game to potential participants and parents. This was supported by the distribution of educational materials in schools, and the TV promotion of the event. At stage 2 (Contemplation), drama workshops in local schools and other special projects in the community created further interest into the women's game. In Stage 3 (Preparation), ticket promotion and taster opportunities enabled spectating and/or participation. Stage 4 (Action) offered live or TV spectatorship and additional participation via competitively structured activities. Stage 5 (Confirmation/maintenance) presented leader, coaching and refereeing awards to sustain involvement in the sport.

\section{DISCUSSION}

The EURO 2005 legacy programme established wider social objectives than 'just football' through collaboration with the North West Development Agency (NWDA) i.e. in promoting investment, skills and employment. Some of the venues may have been considered more 'fertile ground' for building an audience for the sport, as they were located in areas of some considerable activity for women's sport and football, such as Blackburn. On the other hand, some of the venues were not in areas with established local networks and in the case of Warrington, the games took place in the town's Rugby League stadium. Nevertheless, crowds at the event were above the expectations of UEFA and the FA, as were TV viewing figures. However, the necessity to generate revenues through sponsorship resulted in 'mixed messages' being sent out to the predominantly youthful audience in the stadia.

Social marketing, in seeking to influence both individual and social changes, appeared to have some merit when considering the desire to grow the numbers of participants and general engagement with physical activity. The programme created awareness through road shows, persuaded and motivated through workshops, facilitated action via taster sessions and the continued support of football through competitive structures, and lead to opportunities to maintain behaviour change through involvement in leadership, coaching and officiating. As a result, the marketing activities performed by the legacy programme, arguably, did much to present the social proposition of women's football in line with the model of 'social sport marketing'. However, positive approval of the legacy programme is tempered somewhat due to inconsistencies with the messages of commercial marketing of event sponsors. Nevertheless, the desire for positive social change through this tournament was undiminished.

\section{REFERENCES}

Beishon, M. (2005) "Brand New Approach" http://www.hda.nhs.uk/1204/marketing.html

Collins, M. (2004) “Framework for the Future?” Sports Management. Vol. 8 Issue 2: 61-63.

MORI (2004) MORI Sports Tracker 1996-2004, Report October 2004.

Peattie, S. \& Peattie, K. (2003) "Ready to fly solo? Reducing social marketing's dependence on commercial marketing theory" Marketing Theory. Volume 3 (3): 365-385. 
Prochaska, J. O. \& DiClemente, C. C. (1983) 'Stages and Processes of Self-Change of Smoking: Toward an Integrative Model of Change', Journal of Consulting and Clinical Psychology, Vol. 51: 390-95.

Strategy Unit (2002) “Game Plan: a strategy for delivering Government's sport and physical activity objectives" A Joint DCMS/Strategy Unit Report: London.

Williams, J. (2003) A game for rough girls? A history of women's football in Britain, London: Routledge. 